\title{
"I Had Barbara": \\ Women's Ties and Wharton's "Roman Fever"
}

\footnotetext{
$T$
}

he setting of Edith Wharton's short story "Roman Fever" (1934) is consciously casual. Two wealthy American widows with "time to kill" (10) sit chatting through the afternoon, on the terrace of a restaurant in Rome, overlooking the ruins of the ancient city. They have known each other off and on all their lives. Both have daughters who are presently out together with two eligible young Italian men, and the women recall their own courting days, also together, also in Rome. There is a risky edge to this talk because they had both been in love with the same man and knew it at the time. One of the women had been engaged to him, and duly married him, yet it is she, Mrs. Slade, who now asks herself, in relation to the other, "Would she never cure herself of envying her?" (17)-and who pushes the conversation forward with further questions.

In its final pages, the story moves into high gear with the disclosure, one after another, of three interlocking secrets from that time. Mrs. Ansley had received a letter from Delphin Slade inviting her to meet him one night at the Colosseum. The first thrust comes from Mrs. Slade,

Volume 17, Number 3 DOI 10.1215/10407391-2006-010

(ㄷ) 2006 by Brown University and $\mathrm{d}$ i f f e $\mathrm{r}$ e $\mathbf{n}$ c e $s$ : A Journal of Feminist Cultural Studies 
who declares that it was she, out of jealousy, who wrote that letter, in an attempt to trick her rival into a dangerous adventure. (Behind the stratagem lay the story of a great-aunt who, by sending her sister out one cold night to the Forum "because they were in love with the same man" [18] had caused her death.) For Grace Ansley, this ruins the memory of "the only letter I ever had from him" (21), and Mrs. Slade's triumph seems to be confirmed. But then-return blow-Mrs. Ansley reveals that the date did in fact take place (she had replied to the letter). Mrs Slade recovers from this with difficulty:

"I oughtn't to begrudge it to you, I suppose. After all, I had everything; I had him for twenty-five years. And you had nothing but that one letter he didn't write." (24)

With perfect pacing, Wharton then completes the series of revelations and reversals, ending the story like this:

Mrs. Ansley was again silent. At length she turned toward the door of the terrace. She took a step, and turned back, facing her companion.

"I had Barbara," she said, and began to move ahead of Mrs. Slade toward the stairway. (24)

"I had Barbara" is the clinching shock announcement. We take it to mean, as must Mrs. Slade, that sex took place that night at the Colosseum and that Delphin Slade was the father of Barbara Ansley. The scandalous information then appears to sort out several doubts and suspicions that Wharton has carefully planted during the course of the narrative. Mrs. Slade envies Mrs. Ansley her bright, "dynamic" daughter Barbara and cannot understand how two such "exemplary characters" as Grace and Horace Ansley could have produced her (16-17); she, meanwhile, is disappointed in her own too perfect Jenny. Grace had been ill after her late-night "sightseeing" (19) all those years ago, and she was "married to Horace Ansley two months afterward" (22). If Barbara is now shown to be Delphin's daughter, then these anomalies seem to be cleared up: Grace was quickly married because she was pregnant, and Barbara is after all the daughter of the dynamic Delphin Slade.

Grace Ansley's punchline-"I had Barbara"-rounds off the series of blows initiated by her ancient rival. A final detail appears to confirm that the relations between the two women have shifted, as Mrs. Ansley, 
previously seen as the more timid and passive of the two, "began to move ahead." Thus, the battle that has taken place this present afternoon seems both to repeat and complete the one that occurred a generation before. Then, Alida had taken the initiative in attempting to punish Grace for her interest in her fiancé. She sent the fake letter that was meant to lead to a long, lonely wait at the entrance to the Colosseum, but in fact her action had had the effect of bringing about exactly what she was seeking to avoid, a rendezvous between the two potential lovers. Today, unaware of what happened between Grace and Delphin as a result of her letter, Mrs. Slade has been continuing to attempt to control the future. Her renewed jealousy of Grace is prompted by a "prophetic flight" (17) in which she imagines Grace settled in grandmotherly contentment near her sparkling daughter's family. It is this fantasy_ "Would she never cure herself of envying her?"-that sets off the conversational prod that is meant to humiliate Grace once more but instead-and again as before-has the opposite result.

When the story is reread in the knowledge of what is revealed at the end, many phrases seem to take on a second, confirming meaning that did not appear the first time. One of the girls is described as a "rare accident" (14). The two women are "old lovers of Rome" (11). Grace's knitting collapses in "a panic-stricken heap" (20); “one, two, three-slip" (16) seems to point to a fall, not a pattern. Violence is everywhere: in "so purposeless a wound" (21), verbally inflicted, or in the "time to kill," where the leisurely cliché now sounds openly murderous-time to kill. On the second reading, we see significance in the "mutual confession" (13) that first seemed only to refer to middle-aged women's regret at the dullness of their lives in comparison with their daughters'. Great-aunt Harriet, who had sent her sister out to her death, "confessed it years afterwards" (18), just as Mrs. Slade owns up to her own attempt to follow the great-aunt's example. Long ago, when she was the Ansleys' neighbor in New York, Mrs. Slade had joked that "I'd rather live opposite a speak-easy for a change" (12): belatedly, the speak-easy's double suggestion of transgression and confession has now turned the jibe against her.

In going over the story again and finding hitherto unnoticed indications of what happened - the old story that the current story brings out-we are in the same position as the two women characters. They find themselves engaged in a process of reinterpretation and reconstruction as they go back over the events of twenty-five years before, as well as over their subsequent views of the other: "So these two ladies visualized each other, each through the wrong end of her little telescope" (14). Each has 
partial and sometimes mistaken knowledge, and the present conversation brings out what had previously been hidden from both. Seemingly tangential elements in the narrative also suggest, the second time, the need for this kind of reappraisal of the situation, by readers and protagonists alike. Mrs. Ansley concurs with her companion's remark about the "beautiful" view of the Palatine from where they are seated:

"It always will be, to me," assented her friend Mrs. Ansley, with so slight a stress on the "me" that Mrs. Slade, though she noticed it, wondered if it were not merely accidental, like the random underlinings of old-fashioned letter-writers. (Io)

On the second reading, we know, as Mrs. Slade has also found out, that there is more of a "me" in Grace Ansley than had been imagined. She did not initiate, but she did go along with, the illicit tryst with Delphin Slade. Also, the very idea of the "merely accidental" is discredited in this story: accidents happen not by chance, but in relation to particular designs and purposes that go wrong-both those in the past and those in the present conversation. "Like the random underlinings of old-fashioned letterwriters"? After the first reading, we know that in this story there need be nothing random or simply decorative about an old-time letter like the one Alida Slade once signed with the initials "D. S."; nor are oldfashioned ladies, like Great-aunt Harriet, as innocent or haphazard in their designs as might be thought. Whatever the truth of the "tradition" (18) of Harriet's youthful misdemeanor, as a tale it was effective both as a deterrent-"Mother used to frighten us with the story," says Grace-and as an example to follow, as Alida then did when "you frightened me with it" (19): Mrs. Slade's characteristically conscious "stress on the 'me.'"

If the interpretation and use of stories is an issue within this one, there is also overt reference, by both characters and narrator, to confusions between different levels of language, making it difficult to know which elements are to be taken as central to a main story and which as "merely" metaphorical or accidental. "Well, I mean figuratively" (9), Barbara is heard to say to Jenny as the two depart; "figuratively" here refers to metaphorical knitting, which in fact is what Grace will literally be doing on the next page, though with additions of emotion and opulence that immediately detract from the bare fact: "Half guiltily"-another phrase that resonates differently on the second reading-"she drew from her handsomely mounted black handbag a twist of crimson silk run through by two fine knitting needles" (10). Sliding into suggestion, literal 
knitting becomes ominous once more-"one, two, three-slip."1 In New York, when their husbands were alive, Grace and Alida "had lived opposite each other-actually as well as figuratively-for years" (12), the two wouldbe contrasting adverbs thrust into the middle of an otherwise innocuous clause and raising a question about how, exactly, their meanings are to be understood. At one point, Mrs. Ansley takes up her knitting "almost furtively" and Mrs. Slade takes "sideway note of this activity" - as though furtive, or almost furtive herself, but also, in this story, as a matter of marginal uncertainty: only in light of the later revelations is it clear which gestures and which words need to be actively noted or interpreted. And at almost the end, when "[a] stout lady in a dust-coat suddenly appeared, asking in broken Italian if any one had seen the elastic band which held together her tattered Baedecker" (23), she seems to be both a crazy diversion, a trivial distraction from the suspended drama, and also, equally, a comically allegorical sideshow of the unraveling- "broken" language, broken guidebook- of previously settled stories of the ladies' youthful past.

Whether trivially touristical or highly serious-as always, in this story, both and either are possible-allusions to classical culture are scattered throughout "Roman Fever." The letter from "Delphin" proves oracular in its production of a future event. The story's setting above the ruins of Rome provides the backdrop for the emergence of long-buried stories and for the gladiatorial violence of Mrs. Slade/"slayed." As in a Greek tragedy, Mrs. Ansley's face shows a "mask" (20); at one point, she "looked straight out at the great accumulated wreckage of passion and splendour at her feet" (17). In its own minor key, the story could even be taken as a modern version of Oedipus the King. As in Sophocles' drama, what happens is not so much a new action as a conversation that, driving to its painful dénouement, goes over ancient events, showing their significance to be quite different from what participants had imagined. Oedipus finds that a man he once murdered was his own father; that Polybus, the man he thought was his father, was not; and that Jocasta, the woman he married, was his birth mother. In "Roman Fever," too, there is a revelation involving both illicit sexuality and mistaken paternity. The two families that "actually, as well as figuratively" "lived opposite each other" are in one sense the same family-more actually than "actually" first suggested-conjoined by girls who turn out to have the same father. In "Roman Fever," the attempt to ward off a feared event precipitates its happening; and so for Oedipus, the fulfillment of the oracle that he shall murder his father and marry and have children with his mother is enabled 
by the successive attempts, by his birth parents and later himself, to avert it (the newborn baby is exposed and so does not know his own parents; the young man flees those he wrongly thinks are his parents, and thereby encounters first Laius and then Jocasta).

To make such a grand comparison is perhaps to do an injustice to "Roman Fever," a story without such classical or universal affiliations-or destinies-as Sophocles' Oedipus. For one thing, there is nothing at stake in the modern tale beyond the private concerns of two well-off, unoccupied women. In Oedipus, on the other hand, the inquiry that leads eventually to the discovery of Oedipus's other history, his "true" identity, is initiated-by Oedipus himself-as a matter of social urgency: the city is suffering from a plague and the oracle has said that the person responsible for the pollution, Laius's murderer years ago, must be tracked down. The strong point of likeness between the ancient drama and the modern story is that in each the action consists only of conversation and its accompanying emotions; words alone have the effect of changing the sense of past events and, thereby, of changing the characters' understanding of themselves and their histories in the present time.

It would also be possible, in different ways, to look at "Roman Fever" as a female version of the Oedipal paradigm. Freud adopted Sophocles' drama as his literary template for thinking about children's-essentially, boys'-development to adulthood, from early years of incestuous longings and rivalrous hatred out into the wider world of the cultural community in which the loss of their princely uniqueness_ "His Majesty the Baby" ("On Narcissism" 91) - was compensated by the adult privileges of a life beyond the confines of the first family. The girl had no comparable story; rather, in Freud's attempts to consider her different development, she ended up only-at best-a misfit, forever unconsciously seeking the masculinity of which she was deprived. Feminists since Freud have regularly protested against this overt secondarization of femininity, but many, too, have understood the theory as a useful allegory of the difficulties of women's psychological placement in a patriarchal society. In this context, "Roman Fever," written quite literally from the women's point of view, as Grace and Alida sit overlooking the valued remains of a violent masculine civilization, might seem to lend support to two different perspectives on women's lives in a modern but age-old patriarchal culture.

From the first point of view, Mrs. Ansley and Mrs. Slade have both lived the conventional feminine lives of girl, wife, mother, and widow; their identities have been primarily in relation to husbands secured, then 
lived with, then lost. Mrs. Slade was proud to see herself admired as "the Slade's wife" (13). After the death of her husband and, prior to that, of their son, "[t]here was nothing left but to mother her daughter" (13), presented less as compensation for her losses (Jenny's, too) than as a poor third choice. "[N]othing left but [. . .]" also seems to echo the ennui that has led to the two ladies' spending the afternoon talking-the equivalent, on this particular day, of the third-choice outlet for unused energies. "[S]ometimes I get tired just looking-even at this," says Grace; "Her gesture was now addressed to the stupendous scene at their feet" (10). With nothing going on in their own lives-no one to tend-the women are jaded sightseers, and conversation is tediously time-killing before it turns violently ladykilling.

The differences she thinks she sees from her "opposite" side cause Mrs. Slade to rank both herself and her marriage far above Grace and Horace Ansley, whom she dubs "two nullities" (12); but it is also stressed that the two women's life stories have been virtually identical. They married, they had children, they "lived opposite each other," their husbands died; now, "[t]he similarity of their lot" (13) has brought them back together. Their daughters are repeating or continuing the same old story of girls, in each generation, finding husbands. Within it, there are minor historical variations to do with local conditions and the degree of restraint placed upon the young ladies, but it is essentially the same narrative that is likely to involve rivalry between two girls for the same man. Great-aunt Harriet is the most ancient version of this, and Alida takes it for granted that the same thing is going on between her daughter and Grace's right now. ${ }^{2}$

The lack of individuality that this entails is specified by Grace in response to Alida's reaction to the mockery of the disappearing daughters:

“That's what our daughters think of us!"

Her companion replied by a deprecating gesture. "Not of us individually. We must remember that. It's just the collective modern idea of Mothers." (Io)

Later, this suggestion of historical determinations is elaborated and corroborated in Mrs. Slade's version of maternal Roman history:

"I was just thinking," she said slowly, "what different things Rome stands for to each generation of travellers. To our grandmothers, 
Roman fever; to our mothers, sentimental dangers-how we used to be guarded!-to our daughters, no more dangers than the middle of Main Street." (IS)

What looks like a semisociological objectivity in this account becomes less striking when it turns out that Mrs. Slade is about to provoke with "the spice of disobedience" (16) that drew girls out in their own generation. But still it remains true that both women think back through their mothers, and their foremothers' daughters, just as their focus today is on their own daughters' amorous adventures. This could be seen as further evidence of their subordination to the underlying patriarchal arrangements, in which mothers protect, more or less, and daughters escape, more or less, until the point where they settle down ready to repeat the story in a new form a generation later; but it also points to the other feminist perspective through which the female relationships of "Roman Fever" might be considered.

For it could be said that far from being victims of men, collectively or individually, the women of "Roman Fever" are the drivers of the plots; it is they, not the husbands or boyfriends, who control what happens. No men appear in the present scene of the story, apart from unidentified waiters of another class and nationality than the protagonists, whose role is no more than to let the ladies sit on through the afternoon. The young Italian men with whom the daughters are spending the day feature only as the presumed objects of the girls' predatory desires: “[I]f Babs Ansley isn't out to catch that young aviator-the one who's a Marchese-then I don't know anything" (16). In the past that the conversation brings up, Delphin Slade and Horace Ansley are given purely reactive or passive roles. Delphin goes to the assignation with Grace because he receives her reply to the letter sent in his name. Horace appears in several dual situations with his wife-one of "those two nullities," "two such exemplary characters," "just the duplicate of his wife" (12). Here, he has no distinctive character and no masculinity of his own; they are two of a dull kind, he second ("duplicate") to her. At one crucial point, he is engaged in a doubly passive situation, after Grace's unspecified "illness" when, according to Alida, "[a]s soon as you could get out of bed your mother rushed you off to Florence and married you" (22-23). Horace is merely the accessory groomed for a mother's swiftly pragmatic arrangement of a daughter's wedding; in fact, he is not even mentioned, so that the marriage appears, syntactically, to take place between mother and daughter alone.

In this second view, it is women who call the shots, even if their sphere of influence remains that of the family and marriage. ${ }^{3}$ From 
generation to generation, what takes place is a female negotiation over men. There is also the suggestion that despite appearances, the primary relationships of women are not with men so much as with one another. Babs and Jenny go around as a pair. Alida and Grace "had been intimate since childhood" (12). They are introduced at the start of the story as a kind of dual subject:

From the table at which they had been lunching two American ladies of ripe but well-cared-for middle age moved across the lofty terrace of the Roman restaurant and, leaning on its parapet, looked first at each other, and then down on the outspread glories of the Palatine and the Forum, with the same expression of vague but benevolent approval. (9)

They move as one, they lean as one, and their expression is the "same" one. "Mrs. Slade and Mrs. Ansley had lived opposite each other-actually as well as figuratively -for years": a cohabitation, figuratively if not actually, alongside their marriages. When, prior to the final exchange of secrets, the two fall silent, "Mrs. Ansley was slightly embarrassed by what seemed, after so many years, a new stage in their intimacy" (15). It is crucial, too, that the only declaration of love represented in the story is from woman to woman, the letter to Grace that was written by Alida.

Division and rivalry are also part of this two-in-one, with the facing Upper East Side windows functioning like mirrors that both separate and join the two women as one and as two, self and image "opposite." There are also the metaphorical distorting telescopes through which "these two ladies visualized each other, each through the wrong end." "You think me a monster!" Mrs. Slade bursts out after confessing to her writing of the precious love letter; but then a few lines further down, reflecting on Grace's treachery in getting together with her fiancé: “Wasn't it she who was the monster?" (22). Each woman projects onto the other the features dissociated from herself or exaggerates the assumed differences that make them so conveniently contrastable and comparable, like their supposedly divergent daughters.

There is a further way in which the primacy of woman-towoman relationships comes through as a buried possibility in this story. The closing "I had Barbara" appears, initially, to be dramatic and euphemistic shorthand for "Your husband was the father of my child"; it is a formally symmetrical riposte to "I had him for twenty-five years" (24). In the context of what has been said about Barbara's unusual and emphasized "edge" and the doubt about "where she got it, with those two nullities as 
parents" (12), the line's ultimate reference to paternity seems to explain a minor mystery as well as produce a personal scandal. Everything we have heard up to this point would suggest the likelihood of this other parentage, once it is mooted, while the whole argumentative force of the struggle between the two women seems naturally to come to an end with the decisive reversal.

But what Grace Ansley actually, not figuratively, says is that she had Barbara. She does not say she had sex with Delphin on that night-or that Delphin is Barbara's father. The simple meaning of her statement of motherhood escapes notice, is overlooked, because it is what we and the characters already know: sure, Grace had Barbara, Barbara is Grace's daughter. Maternity is never in doubt; paternity has been, throughout the history of human storytelling, the question-generating status. This is what leads us as readers, and presumably Alida Slade as well (no reply is actually given), to interpret Grace's announcement as supplying new information, clinching the story with the utterance of an age-old species of female secret. And to all intents and purposes, it makes no difference whether Grace meant to speak more than her words or not, since the dramatic effect is exactly as if she had: "She began to move ahead of Mrs. Slade toward the stairway" (24) - end of story.

Yet, if we look again at the evidence that the closing statement seems to support, it turns out that it, too, involves elisions. For if Barbara is Delphin's daughter, she is still, surely, Grace's as well. So there is still, in Alida's terms, a problem about how one of "two such exemplary characters as you and Horace had managed to produce anything quite so dynamic." Even more strikingly, no doubt is raised at all about the equally anomalous quiet daughter of "the exceptional couple," the Slades (13). Dull Jenny has not only come from "the Slade" (13) but from a mother known for her "vividness"” (14): more than Babs, she has two inexplicable parents, not just one. While we may go with the rhetorical flow of the final sentences, it does not, on closer inspection, sweep away the kinship questions that the story has explicitly raised (in the case of Babs) and, following the same logic, suggested (in the case of Jenny). ${ }^{4}$ The story leads us to accept that a daughter should be "like" her father or "like" her parents. The missing connection, between her and her mother, could then be seen as the one surreptitiously supplied by "I had Barbara."

It turns out, then, that there may be more to the ambiguity of "I had Barbara" than a formal point about narrative undecidability. "I had Barbara," in its lovely literalness, says nothing about a father; instead, it 
matches a desirable daughter against Mrs. Slade's boast of having had "him," that husband or father. There is no second parent in view: in the singular, "I" had Barbara. In this sense, the hidden victory of "Roman Fever" goes to a same-sex bond and to the connection of mother and daughter elided and downgraded by paternal kinship relations. ${ }^{5}$

Yet the opposition between the known, literal mother and the inferred and doubtful father may seem, from another point of view, too neat an affirmation of what is itself a classically patriarchal division. "Pater semper incertus est," as Freud puts it in his essay "Family Romances," using the Latin legal phrase; and if the father is always uncertain, then the mother, at the other extreme, is superlatively certain, "certissima" (239). This is the distinction that comes, Freud argues, to enter into every child's understanding of the relations between the sexes; and it is never abandoned, remaining the basis of adult thinking. Freud is individualizing a theory put forward by nineteenth-century anthropologists, who saw a crucial and progressive turning-point in the alleged move made by primitive cultures from matriarchal to patriarchal thinking. This is how he puts it himself in Moses and Monotheism:

[I] t came about that the matriarchal social order was succeeded by the patriarchal one-which, of course, involved a revolution in the juridical condition that had so far prevailed. An echo of this revolution seems still to be audible in the Oresteia of Aeschylus. But this turning from the mother to the father points in addition to a victory of intellectuality over sensuality-that is, an advance in civilization [Kulturfortschritt], since maternity is proved by the evidence of the senses while paternity is a hypothesis, based on an inference and a premiss. Taking sides in this way with a thought-process in preference to a sense perception has proved to be a momentous step. (II3-I4)

This vaunted cultural progress comes about because bodily evidence is replaced by intellectual evidence, logically consistent ("based on an inference and a premiss”) but necessarily fallible (no DNA testing yet). It seems, at best, a shaky shift, confirming rather than canceling the fragility of fatherhood as a category.

Read in its connotative sense, as we initially take it, "I had Barbara" succinctly combines a patriarchal logic ("he's the father") with the maternal self-evidence ("I gave birth to her") that allegedly needs no proof. But it subordinates, as culture does, the obvious, "sensual" side, within the 
closing logic of the story and the overt rivalry between the two women. In its maternal rather than paternal emphasis, "I had Barbara" goes without saying and therefore does not figure: it is what is already known and is thereby passed over in the context of the other available meaning. ${ }^{6}$ It is ironically apt, in this context, that the name Barbara originates in the feminine form of the ancient Greek word for the non-Greek, non-civilized

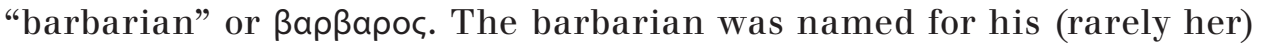
incomprehensible language, sounding to Greek ears like a meaningless repetition ("bar . . . bar"); he did not enter into the community defined by its logos: logic, reason, and language. What Grace Ansley "had" was (in both senses) out of order-a wild child, as yet unassimilated to patriarchal civilization. Like any baby, but especially like any girl.

There are other tensions concealed in the phrase "I had Barbara." To begin with, "I" is apparently "I as opposed to you": you had him for all those years, but Barbara is what I had. But it is also, obliquely, a claim to maternal autonomy: "I" not "we." Here, both "fathers"-the likely biological one and the one who raised her-are dismissed from having had Barbara. Only "I" "had" her, even if an illicit paternity is also being asserted. But what does it really mean, even for a mother alone, to "have" Barbara or to have "had" Barbara? In this connection, the simple statement of maternity opens out into more than one possibility. "Having" a baby is what women do at the point of birth; it is the specific point of separation. But Grace has also implicitly "had" Barbara for the twenty-five years that Alida "had" Delphin; the daughter represents a long-term affective tie, begun but not defined by giving birth. "I had Barbara" all that time: better than having had "him," boy baby or husband.

When I first read "Roman Fever" twenty-odd years ago, the less obvious because so obvious maternal meaning of "I had Barbara" seemed to me interesting mainly because of the way it could be used to illustrate the instability even of texts that seemed most tightly stitched together-actually as well as figuratively. "One, two, three-slip": meaning was never so sure, nor destinies and pasts so safely patterned or predictable, as they might appear. In this particular development, orderly in its own consciously dis-ordering fashion, a structuralist analysis à la early Roland Barthes must needs give way to a more deconstructive openness to the misfit elements in a text: the theoretical emphasis was moving on, now allowing for movement and "give" in the object of study as well. 
A generation on from that moment, something else has happened to the solely maternal meaning of "I had Barbara." In light of developments occurring elsewhere than in theory, the statement has lost its apparent literal simplicity of contrast to an inferred, assumed, and disputable father. Today, single parenting can be seen and experienced as a positive choice, and many women are adopting children-for the most part daughters - on their own. The words thus acquire a different historical resonance, in relation to subsequent possibilities and patterns of mothering or having a daughter. No "prophetic flight" of Alida Slade's, fearful or fantastic, could have seen these changes on the horizon; today, they may give Grace Ansley's closing statement about her past the surprising twenty-first-century gloss of a different female future.

Many thanks to Mary Ann O'Farrell, David McWhirter, and others at Texas A \& M University for inspiring discussions about "Roman Fever" in April 2005.

rachel воwlby is Northcliffe Professor of Modern Literature at University College London. Her most recent book is Carried Away: The Invention of Modern Shopping (Columbia University Press, 2001). Freudian Mythologies: Greek Tragedy and Modern Identities will appear in 2007 (Oxford University Press).

1 In another way, the description of Grace's luxurious bag opens up metaphorically onto the silky secret of something soft that was "run through" by two different thrusting instruments.

2 Annamaria Formichella Elsden argues that there is a distinct progression for each successive generation of women. Mrs. Slade's handling of the waiters is Wharton's suggestion of how far (American) women have come since the nineteenth century. Their daughters' repetition of the old story is only in Mrs. Slade's projection; today they are flying high above the "bad air" of the old dangers of "Roman Fever" (malaria). "Even more than their mothers, Barbara and Jenny are able to take command of the foreign environment" (123); "the accuracy with which Mrs. Slade reads the situation and the poise with which she manipulates circumstances indicate her independence and efficacy and allow her to get what she wants" (122). It is certainly true that we are told nothing of Babs and Jenny's real relations with each other, their mothers, or their men, which leaves it entirely possible that there may be real differences from the previous generation. But we cannot know for sure. It is Mrs. Slade's own attempts to "read" then react to situations, to "take command" or "manipulate circumstances," both in the past and in the course of the present conversation, that form the story of her failures.

3 It is here that Wharton's perspective differs markedly from that of its precursor text, Daisy Miller (1878). Henry James's story focuses on a contemporary American girl whose uncautious behavior in Rome, including a late-night visit with a man to the Colosseum, ultimately 
leads to her contracting Roman fever-malaria-and dying. Daisy is filtered through the perceptions of an observing American man who is fascinated, attracted, judgmental, and ultimately critical of his own prejudices. Daisy's point of view is never given; the story is, rather, concerned with the man's responses to a modern girl who assumes a freedom that ignores the conventions of sensible or respectable conduct. Wharton also uses the idea of Roman fever differently. In a previous generation-the Daisy Miller generation-Great-aunt Harriet's sister did die of it, but what Grace Ansley caught as a result of her Roman night out was pregnancy, initially represented as an illness only in order to conceal it. Within the story, it is historically distanced: "[W]hat different things Rome stands for to each generation of travellers. To our grandmothers, Roman fever [. . .]." Malaria had, in fact, ceased to be the real threat it had been in nineteenth-century Rome. But Roman fever's title role makes it also function for Wharton's story like a catch-all, semi-euphemistic diagnosis of wayward sexual behavior in young American women abroad.

4. My argument here is similar to Jonathan Culler's in relation to Oedipus the King. In "Story and Discourse in the Analysis of Narrative," Culler points out that the claim more than once in Sophocles' tragedy that there were "many murderers" of King Laius, not just one, is never disproved; rather, it is forgotten in the face of the compelling convergence of narratives that leads us, like Oedipus himself, to be convinced that he was the murderer.

5 Dale M. Bauer sees equally transgressive implications in the primary interpretation of "I had Barbara": "Grace threatens the symbolic order of society by exposing the arbitrary assumption Alida makes about Babs's father, not to mention the assumption about Grace's respectability" (160).

$6 \quad$ Here, especially, my thinking is indebted to Barbara Johnson's, and in particular, at this point, to "Is Female to Male as Ground Is to Figure?"

\section{Works Cited}

Bauer, Dale M. Edith Wharton's Brave New Politics. Madison: U of Wisconsin P, 1994.

Culler, Jonathan. "Story and Discourse in the Analysis of Narrative." The Pursuit of Signs: Semiotics, Literature, Deconstruction. London: Routledge, 1981. 169-87.

Elsden, Annamaria Formichella. Roman Fever: Domesticity and Nationalism in NineteenthCentury American Women's Writing. Columbus: Ohio State uP, 2004.

Freud, Sigmund. The Standard Edition of the Complete Psychological Works of Sigmund Freud. Trans. and ed. James Strachey. 24 vols. London: Hogarth, 1955-74.

"Family Romances." 1909. The Standard Edition. Vol. 9. 237-41.

Moses and Monotheism. 1939. The Standard Edition. Vol. 23. 6-137.

“On Narcissism: An Introduction.” 1914. The Standard Edition. Vol. 14.

73-102

James, Henry. "Daisy Miller". 1878. Daisy Miller and Other Stories. Ed. Jean Gooder. Oxford: Oxford World's Classics, 1985. 
Johnson, Barbara. "Is Female to Male as Ground Is to Figure?" The Feminist Difference: Literature, Psychoanalysis, Race, and Gender. Cambridge, MA: Harvard up, 1998. 17-36.

Wharton, Edith. "Roman Fever." 1934. Roman Fever and Other Stories. London: Virago, $1983 \cdot 9-24$. 